* Doutor em Direito do Estado pela USP (2010). Mestre em Direito Civil pela USP (2000). Graduado em Direito pela USP (1993). Professor do Curso de Mestrado em Direito da Sociedade da Informação no Centro Universitário das Faculdades Metropolitanas Unidas - São Paulo. Estado de São Paulo. Juiz Federal em São Paulo. Email: marcelo. martins@fmu.br.

** Mestrando em Direito da Sociedade da Informação pelo Centro Universitário das Faculdades Metropolitanas Unidas - São Paulo. Estado de São Paulo. Pós-graduado lato sensu em Processo pela UNAERP (2013). Possui graduação em Direito pelo Centro Universitário de Rio Preto (1997). Advogado. Email: m-tadeu-nascimento@uol.com.br.

*** Mestrando em Direito da Sociedade da Informação pelo Centro Universitário das Faculdades Metropolitanas Unidas - São Paulo. Estado de São Paulo. Especialista em Direito Civil e Processo Civil pela Escola Paulista de Direito. Especializando em Direito Constitucional e Direito Administrativo pela Escola Paulista de Direito. Especialista em Direito Ambiental Empresarial pelo Centro Universitário das Faculdades Metropolitanas Unidas. Graduado em Direito pela Universidade São Judas Tadeu. Advogado. Email: ronnymaxm@yahoo.com.br.

\section{Os Novos Serviços na Sociedade da INFORMAÇÃo: O CASO do UBER Na Cidade de São Paulo}

\author{
The New Services IN THE INFORMation \\ Society: the Uber Case in SÃo Paulo \\ CITY
}

Marcelo Guerra Martins*

Marcelo Tadeu Nascimento**

Ronny Max Machado**

Como citar: MARTINS, Marcelo Guerra; NASCIMENTO, Marcelo Tadeu; MACHADO, Rony Max. Os Novos Serviços na Sociedade da Informação: o Caso do Uber na Cidade de São Paulo. Scientia Iuris, Londrina, v. 21, n. 2, p. 154-181, jul. 2017. DOI: $10.5433 / 2178-8189.2017 \mathrm{v} 21 \mathrm{n} 1 \mathrm{p} 154$. ISSN: 2178-8189.

Resumo: $O$ presente artigo tem como foco o serviço de transporte por meio da utilização do Uber, tecnologia típica da sociedade da informação, pautada pela utilização da internet e de equipamentos eletrônicos como tablets e smartphones. São abordados também os aspectos sociais, econômicos e jurídicos dessa novel tecnologia de transporte nas grandes cidades brasileiras, com ênfase na cidade de São Paulo, que regulou o uso do Uber em 2016. As conclusões enfatizam a compatibilidade do 
novo serviço com o sistema jurídico brasileiro, bem como as potenciais vantagens em relação ao transporte realizado pelos taxis tradicionais. A metodologia utilizada é o estudo bibliográfico com caráter qualitativo e indutivo.

Palavras-chave: Sociedade da informação. Globalização. Novos services. Uber.

\begin{abstract}
This paper focuses on transport services, specifically Uber - a typical tool of our information society, which is a consequence of the widespread use of the Internet that manifests itself in electronic devices such as tablets and smartphones. This study also discusses the social, economic and legal aspects of this novel transportation technology in the context of large Brazilian cities - giving special emphasis to the city of São Paulo, which regulated the use of Uber in 2016. Finally, this paper highlights the compatibility of this new service with the Brazilian legal system, as well as its potential advantages over traditional taxi transportation. Moreover, the preferred method utilized in this research is literature review, which has some qualitative and inductive aspects.
\end{abstract}

Key words: Information society. Globalization. New services. Uber. 


\section{INTRODUÇÃO}

O objetivo do presente trabalho é abordar os aspectos jurídicos, econômicos e sociais dos novos serviços que surgem na sociedade da informação, principalmente o transporte individual oneroso intermediado pelo aplicativo Uber que, verdadeiramente, fez eclodir disputas acirradas com os meios tradicionais desse tipo de transporte (os taxistas), com enfoque no caso da cidade de São Paulo, que recentemente regulou o serviço do Uber por meio do Decreto Municipal ${ }^{0}$ 56.981, de 10 de maio de 2016.

Outrossim, o aplicativo é inegavelmente fruto da nova realidade mundial forjada pelo aperfeiçoamento da tecnologia aliada ao fenômeno da globalização, considerada "uma dinâmica que assimila de maneira durável a sociedade mundial, as diferentes regiões do mundo, as nações e as culturas locais" (WULF, 2004, p. 233).

Nos últimos anos houve uma generalizada dispersão de dispositivos eletrônicos como notebooks, tablets e smartphones e de inúmeros aplicativos que quase sempre podem ser "baixados" pela internet, gerando, cada vez mais, intenso compartilhamento de informações, ideias e conhecimento, além da possibilidade da prestação de serviços nunca antes imaginados.

Assim, os novos serviços despontam como preocupação acadêmica, jurídica, econômica e social, com destaque para o Uber que, por estar voltado ao transporte urbano de passageiros, ganhou notoriedade e fama nas maiores cidades do planeta.

A utilização do Uber, cuja operação requer a utilização de um aplicativo compatível com praticamente todos os aparelhos telefônicos celulares, permite que o usuário rapidamente contrate seu transporte 
a um custo presumivelmente mais acessível do que aquele dos táxis tradicionais.

No Brasil, especificamente em São Paulo, a empresa detentora do aplicativo colocou seus serviços à disposição, o que foi bem, de um modo geral, aceito pelos usuários. Porém, há fortes resistências por parte do Sindicato dos Taxistas que insiste na tese de que por ser o serviço do Uber idêntico aos dos táxis, deveria não ser coibido pelas autoridades competentes por falta da devida regulamentação.

É fato que tal embate levou o Município de São Paulo a regular o transporte por meio do Uber, diferenciando-o do realizado pelos taxistas. Este será, especificamente, o cenário que recairá as reflexões do presente estudo, com as conclusões de que estes serviços fomentam a economia local e tornam mais acessível o transporte público urbano. A metodologia utilizada é o estudo bibliográfico com caráter qualitativo e indutivo.

$\mathrm{O}$ presente estudo se justifica na medida em que adensa a produção do conhecimento sobre o tratamento jurídico de novos serviços surgidos dentro do contexto da sociedade da informação, cujos reflexos sociais e econômicos são inegáveis.

Assim, nos itens que seguem, será inicialmente tratada a questão da globalização, das novas tecnologias e dos serviços que surgem na sociedade da informação, partindo-se, em seguida, para as especificações do serviço do aplicativo Uber e sua operação no Brasil, especificamente na cidade de São Paulo. Ao final, as conclusões apontarão para a legalidade da atividade de transporte por meio do Uber, inclusive pelo fato de diferenciar-se da atividade desenvolvida pelos taxistas.

\section{AGLOBALIZAÇÃO E OS SERVIÇOS NASOCIEDADE DAINFORMAÇÃO}


Tomando-se o fenômeno da globalização como uma dinâmica engendrada pela sociedade mundial, segundo Wulf (2004, p. 233-234), antropólogo da Universidade Livre de Berlim, notabiliza-se cinco diferentes elementos de grande importância, a saber:

(i) a globalização dos mercados com o desaparecimento das barreiras comerciais, o aumento da movimentação dos capitais e o ganho de influência econômica neoliberal;

(ii) "a globalização das estratégias das empresas e dos mercados, que são estratégias mundiais de produção, de distribuição e de redução de custos por deslocalização";

(iii) "a globalização da pesquisa e do desenvolvimento tecnológico, acompanhada pela elaboração de redes mundiais, de novas tecnologias da informação e de comunicação";

(iv) a globalização de estruturas políticas transnacionais, perdendo os Estados-nações certa influência, desenvolvendo-se organismos e estruturas internacionais;

(v) "a globalização de modelos de consumo, estilos de vida e estilos culturais, que conhecem uma tendência à uniformização". Finaliza Wulf (2004), afirmando que:

O efeito combinado desses elementos cria um quadro de referência para a compreensão do Zeitgeist, para a autocompreensão do homem de nossos dias e, portanto, para as evoluções culturais do presente. $\mathrm{O}$ que é característico, aqui, é o isolamento da economia em relação à esfera política, a globalização das formas de vida e o crescimento da importância das imagens no quadro de uma 'deturpação icônica'.

Para Moreira (2002, p. 268), o fenômeno globalização expressa 
uma maneira de compreender a internacionalização nos relacionamentos entre os povos de todo o mundo. Em suas palavras:

Aglobalização traduzuma idéia de internacionalização nas relações entre os povos, um inter-relacionamento entre os Estados nacionais de modo que identificamos, ao lado destas micro-realidades, uma só região, um só mundo, ou, como dizem muitos, uma verdadeira -aldeia global. Esta única e internacional realidade se reflete inexoravelmente na economia, na política, nos negócios, no direito, etc.

Além disso, a globalização traduz uma nova etapa do sistema capitalista que, com fundamento nos ideais neoliberais, se atenta para as peculiaridades do mercado externo no acirramento do sistema.

Esta peculiaridade foi trazida na necessidade de abertura de novos mercados de consumo, diminuição de custos trabalhistas e redução no papel do Estado como regulador das relações sociais de trabalho e consumo. Assim sendo, um dentre os inúmeros impactos da globalização é facilitar as relações econômicas e sociais entre os indivíduos.

Baumann (1996, p. 37) descreve as dificuldades conceituais a respeito do processo de globalização, no entanto, a busca por compreensão dos efeitos é cada vez mais constante. Nessa linha, diz o autor que:

Em que pesem as dificuldades conceituais, o conhecimento do processo de globalização, suas características e possíveis efeitos torna-se crescentemente necessário, tanto porque esse processo é expansivo por natureza, quanto porque não existem indícios aparentes da sua eventual reversão. 
Com relação ao neoliberalismo, enquanto política de desenvolvimento, é preciso pontuar que ele consiste em um conjunto de ideias políticas e econômicas capitalistas que defende uma menor participação do Estado na economia, em benefício de maior liberdade de comércio, como uma forma de proporcionar o crescimento econômico e o desenvolvimento social de um país.

$\mathrm{Na}$ mesma banda, o neoliberalismo defende a mínima intervenção do Estado no mercado de trabalho, a política de privatização de empresas estatais, a livre circulação de capitais internacionais e ênfase na globalização, a abertura da economia para a entrada de empresas multinacionais, a adoção de medidas contra o protecionismo econômico, a diminuição dos tributos excessivos, etc.

Nesse contexto global, Ianni (1996, p. 190) assevera que a sociedade ainda precisa de muitos aperfeiçoamentos. Em sua lição:

Ocorre que a sociedade global não é mera extensão quantitativa e qualitativa da sociedade nacional. Ainda que esta continue a ser básica, evidente e indispensável, manifestando-se inclusive no âmbito internacional, é inegável que a sociedade global se constitui como uma realidade original, desconhecida, carente de interpretações.

Fato é que, segundo Baumann (1996, p. 37-38), a globalização avança ao longo do tempo sem dar sinais de que o fenômeno está prestes a arrefecer, aliás, muito pelo contrário, aliás. Nesse tópico, diz o autor que:

Uma das peculiaridades que distinguem o processo de globalização de toda experiência anterior é que, como conseqüência de sua forma e intensidade, seus efeitos são mais intensos e se superpõem aos anteriores, além 
de que - à diferença, por exemplo, da regionalização, em que aspectos políticos ou de outra índole podem levar ao fracasso de um processo - por sua própria natureza, sua tendência é de constante ampliação, afetando, embora de forma variada, a todos os países.

Com o avanço da globalização surgem os primeiros eventos inauguradores do desenvolvimento da alta tecnologia e, a partir destes eventos, nasce a expressão sociedade da informação. Segundo Paesani (2003, p. 10), é possível fixar que a expressão sociedade da informação surgiu no ano de 1969 em razão do desenvolvimento da chamada Advanced Research Projects Agency (ARPANET), nos Estados Unidos da América. Pequenas redes locais (conhecidas como LAN) foram criadas e posicionadas em lugares estratégicos do país, e ligadas por meio de redes de telecomunicação geográfica (chamadas de WAN).

Desse modo, se algum ponto estratégico fosse destruído, as redes conexas, compostas por redes locais distantes umas das outras, mas ligadas entre si, blindariam a comunicação por meio das redes coligadas. Esse modelo sistemático de redes interligadas foi chamado de internet ou Inter Networking (PAESANI, 2003, p. 10).

Ao final do século XX e início do presente, a internet tornou-se uma realidade para boa parte da humanidade e seus efeitos podem ser observados na alteração do cotidiano de grande número de pessoas. $\mathrm{O}$ número de usuários da internet vem aumentando significativamente nos últimos anos. Segundo Gomes (2015), “em 2010, os internautas eram 82 milhões, em 2015, passaram a 117 milhões. Já o número de donos de smartphone pulou de 10 milhões para 93 milhões no mesmo período".

Para se ter uma vaga noção, atualmente, a $27^{\mathrm{a}}$ Pesquisa Anual de Administração e Uso de Tecnologia da Informação nas empresas, 
encabeçada pela FGV - Fundação Getúlio Vargas de São Paulo, divulgada em 15.04.2016 (NÚMERO..., 2016), fez um levantamento de que o número de smartphones em uso no Brasil, para maio do mesmo ano, seria de 168 milhões, com uma projeção de 236 milhões em 2018.

Em estudo acerca do que consiste a ideia de sociedade da informação, Takashi (2000, p. 31) contribui apresentando algumas características desse fenômeno:

A sociedade da informação não é um modismo. Representa uma profunda mudança na organização da sociedade e da economia, havendo quem a considere um novo paradigma técnico-econômico. É um fenômeno global, com elevado potencial transformador das atividades sociais e econômicas, uma vez que a estrutura e a dinâmica dessas atividades inevitavelmente serão, em alguma medida, afetadas pela infra-estrutura de informações disponível. É também acentuada sua dimensão políticoeconômica, decorrente da contribuição da infraestrutura de informações para que as regiões sejam mais ou menos atraentes em relação aos negócios e empreendimentos. Sua importância assemelha-se à de uma boa estrada de rodagem para o sucesso econômico das localidades. Tem ainda marcante dimensão social, em virtude do seu elevado potencial de promover a integração, ao reduzir as distâncias entre pessoas e aumentar o seu nível de informação.

A expressão sociedade da informação passou a ser popularizada durante a década de 1980 . Neste mesmo período começam as primeiras manifestações visando a implementação desta ideia por meio de práticas que tiveram seus primeiros movimentos no Centro Europeu de Investigação Nuclear, que possibilitou a inclusão digital e integração das 
pessoas através da internet.

No Brasil a ideia de sociedade da informação teve como evento propulsor no ano de 1997, quando o Ministério da Ciência Tecnologia elaborou o chamado Livro Verde da Sociedade da Informação, cujas finalidades foram a implantação e facilitação de acesso à interação por meio virtual, entre outras.

Ademais, conforme Takahashi (2000, p. 31), o sentido da expressão sociedade da informação, traz em seu bojo a possibilidade de seu estudo sob várias perspectivas.

Portanto, mesmo tendo um conteúdo sociológico, a expressão "sociedade da informação" tem seus reflexos na seara do direito e, por conseguinte, na vida dos indivíduos. A globalização, a sociedade da informação e o direito se conectam em inúmeros pontos que podem ser analisados, entre estes pode se mencionar o surgimento das tecnologias, as práticas transmissoras de informação e o consumo que embasam a análise do presente tema. Nesse sentido, conforme Santos (2011, p. 12):

Trata-se de um processo complexo que atravessa as mais diversas áreas da vida social, da globalização dos sistemas produtivos e financeiros à revolução nas tecnologias e práticas de informação e comunicação, da erosão do Estado nacional e redescoberta da sociedade civil ao aumento exponencial das desigualdades sociais, das grandes movimentações transfronteiriças de pessoas como emigrantes, turistas ou refugiados, ao protagonismo das empresas multinacionais e das instituições financeiras multilaterais, das novas práticas culturais e identitárias aos estilos de consumo globalizado.

Através do desenvolvimento das estruturas tecnológicas, cada 
vez mais se aperfeiçoam os meios de comunicação, com destaque para a telefonia móvel, inclusive com uso da internet, com fortes impactos no desenvolvimento tecnológico, conforme é ressaltado por Cooper et al. (2002, p. 288):

[...] quando pensamos no impacto empírico do fenômeno dos celulares/aparelhos móveis na vida cotidiana, nós descobrimos que a sociologia e a filosofia contém termos que parecem apropriados, mas que têm ou tiveram algumas conotações diferentes: por exemplo, mobilidade social, a problematização da distinção entre público/privado, a transformação estrutural da esfera pública, a metafísica da presença, o fonocentrismo, e, claro, a mobilidade imutável. (Tradução livre).

Pois bem, um dos frutos destes avanços tecnológicos e das mudanças culturais é a questão da economia compartilhada que se transformou em modelo econômico, sendo possível organiza-la em três sistemas.

O primeiro relacionado ao uso, ou seja, as pessoas pagam pelo benefício gerado por um produto ou serviço, sem possuí-lo definitivamente, por isso denominado de Sistema de Produtos e Serviços. (BOTSMAN; ROGERS, 2011, p. 78-79).

O segundo sistema é o de redes sociais (físicas ou virtuais) que possibilitam a redistribuição de mercadorias e produtos usados, os objetos desnecessários em um lugar são direcionados a outro onde encontram utilidade. Cuida-se do Sistema de Mercados de Redistribuição. (BOTSMAN; ROGERS, 2011, p. 124-125).

Por fim, o terceiro sistema corresponde à junção de pessoas 
com interesse comum na troca de ativos não tão tangíveis, como, por exemplo, o tempo, o espaço, as habilidades e o próprio dinheiro. Trocas que ocorrem em nível local e mundial na medida em que a internet possibilita a coordenação, redução e transcendência dos limites físicos. Trata-se do Sistema de Estilos de Vida Colaborativos (BOTSMAN; ROGERS, 2011, p. 180).

Ainda segundo Botsman e Rogers (2011, p. 180), os princípios e as premissas que cercam a economia colaborativa ou compartilhada podem ser resumidos em quatro pilares, quais sejam: (i) a disponibilização de recursos tangíveis ou intangíveis para o engajamento social; (ii) a capacidade ociosa dos produtos ou dos serviços, subutilizados e com potencial de compartilhamento; (iii) a crença no bem comum para os indivíduos; e (iv) a confiança entre estranhos baseada na reputação dos envolvidos.

Frente a essa contextualização, e com a projeção de que a economia colaborativa e rearranjada está em pleno e evidente crescimento, mormente em face da tecnologia, constata-se uma reconfiguração nos modelos clássicos de negócio, na forma como empresas e cidadãos se relacionam, um olhar mais reflexivo sobre o consumo e as relações sociais e políticas.

É dentro desse cenário extremamente dinâmico que nascem os novos serviços, com destaque para o Uber, aplicativo (plataforma digital) para telefones celulares que busca facilitar o transporte de pessoas em grandes cidades por meio da aproximação de prestadores (os motoristas) e consumidores (os passageiros).

\section{O SERVIÇO DE TRANSPORTE UBER}


A ideia de um aplicativo como o Uber nasceu em 2008 na França, a partir das dificuldades de Travis Kalanick e Garret Camp tomarem um táxi na cidade de Paris numa tarde de neve (UBER, 2016). Então, que tal poder chamar um carro a partir de um simples "apertar de botão"?

Passados menos de 10 (dez) anos, ou seja, tempo relativamente curto, o sistema encabeçado pelo Uber está, em grande medida, mudando a maneira de se encarar o transporte das grandes cidades. Segundo o respectivo sítio oficial, o aplicativo está presente em São Paulo e em mais 446 (quatrocentas e quarenta e seis) outras cidades.

Desde o início comercial dessa nova plataforma digital, a empresa proprietária do sistema recebeu muitos investimentos, expandindo suas operações de forma rápida, alcançado após cinco anos o status de startup mais valiosa do mundo, com um valor estimado em US\$ 51 bilhões, tendo ganhado investidores como a Microsoft (O' BRIEN, 2015).

O serviço requer, por meio da utilização de uma plataforma digital, que os possíveis os usuários se cadastrem previamente, fornecendo dados pessoais e um número de cartão de crédito válido. Os motoristas também precisam se cadastrar, além de utilizarem apenas carros em bom estado de conservação e limpeza.

Quando alguém aciona o aplicativo, é localizado o motorista mais próximo, ocasião em que são informados vários dados a seu respeito, bem como do automóvel que fará o trajeto, tais como: marca, modelo, cor, ano de fabricação, placa, nome do condutor.

Realizado o transporte, o pagamento se faz por meio do cartão de crédito antes cadastrado, ficando a empresa Uber com uma parcela, analogamente aos corretores quando a compra e venda de algo é pactuada. 
Em estudo sobre o consumo colaborativo, especificamente a respeito do Uber, Barros (2015) assinala:

A dinâmica ocorre como tantas outras de consumo colaborativo: um aplicativo com um sistema de fácil manuseio e com informações sempre disponíveis promete facilitar a busca por motoristas mais próximos e oferecer um serviço de transporte seguro e com boa experiência. Semelhante aos aplicativos de mobilidade urbana, a Uber faz uso do GPS, demonstra o trajeto do motorista escolhido e o percurso que será realizado com o passageiro, permite que o usuário compartilhe com amigos o caminho e a previsão de chegada, oferece informações a respeito do passageiro e do motorista para a segurança de ambos, faz cotação do valor a ser cobrado pelo trajeto, permite a divisão da tarifa com outros passageiros, dentre outros serviços mais específicos para empresas.

Como o passageiro não divide os custos do trajeto com o motorista, o sistema Uber diferencia-se dos chamados grupos de carona. Também não se trata de serviço de acesso ao público em geral, como é o caso dos táxis, acessíveis que são a qualquer pessoa independentemente de prévio cadastramento.

Desse modo, é de se concluir que o serviço de transporte intermediado pelo Uber é de índole eminentemente privada, notadamente em vista da necessidade de prévio cadastro tanto de motoristas quanto de usuários. Não se cuida, frise-se, de um serviço de acesso ao público.

É certo que o serviço fornecido pelo aplicativo Uber sofreu modificações com o passar dos anos. Nesse sentido, conforme Silva e Andrade (2015, p. 2289):

[...] Inicialmente a startup fazia uso apenas de carros tipo sedan, pelo segmento UberBLACK. 
Contudo, atualmente já oferece outros produtos mais acessíveis, como o UberX, que utiliza modelos de carros mais simples e compactos, e o UberPOP ainda mais competitivo que o anterior por meio de carros compactos. O passageiro deve informar o local de partida e o aplicativo e procura o motorista disponível mais próximo para fornecer o serviço. Para obter uma estimativa de preço, que pode variar a depender de fatores como trânsito e condições climáticas, o usuário deve informar o seu destino. Atualmente, o Uber está instalado em 60 países e não apenas faz uso de automóveis desde os populares ao luxuosos, mas também atua no ramo de aluguel de outros modos, como helicópteros e navios; além de realizar serviços de entrega de mercadorias.

A popularidade do aplicativo vem originando polêmicas severas com taxistas de todo o mundo que, em suma, protestam contra a ausência de regulação precisa para o serviço, o qual não requer registros, licenças ou pagamento de taxas, constituindo, destarte, verdadeira deslealdade de concorrência (SILVA; ANDRADE, 2015, p. 2289).

Para se ter uma ideia, no caso da cidade de São Francisco nos Estados Unidos, a agência municipal de transporte registrou a queda de $65 \%$ (sessenta e cinco por cento) no uso de taxi no período de janeiro de 2012 até agosto de 2014, sendo a principal causa as Transportation Network Companies (TNCS) (SILVA; ANDRADE, 2015, p. 2289-2290).

Reclamações também se originaram em Londres pela Licenced Taxi Drivers Association de Londres, tendo a prefeitura se pronunciado no sentido de tomar medidas para atender as necessidades dos motoristas de táxi, tendo pelo mundo o aplicativo sofrido banimentos em algumas cidades, como em Barcelona, onde somente se autoriza o UberEATS (para entrega de comida), e na Alemanha e Itália, onde o seguimento UberPOP, o qual utiliza motoristas sem licença comercial já se encontra proibido por violar leis nacionais (SILVA; ANDRADE, 2015, p. 2290).

Em suma, o Uber se mostra como nítido exemplo de manifestação do 
consumo colaborativo, algo cada vez mais comum na era da sociedade da informação, conforme visto acima.

Com efeito, nele estão presentes os fatores basilares da sociedade em rede que vivemos atualmente, integrada e conectada por aparelhos eletrônicos de alta tecnologia, convidando o indivíduo a adotar postura mais participativa em face do interesse do grupo, o que, em outras palavras, revela mudança na própria estrutura e no modo tradicional de consumo.

\section{OS ASPECTOS DO UBER NO BRASIL: A REGULAÇÃO EM SÃO PAULO}

A startup teve seu começo no Brasil antes do início da Copa do Mundo de Futebol da FIFA, em maio de 2014, com início em cidades como São Paulo, Rio de Janeiro, Belo Horizonte e Brasília. Como em outras partes do mundo, a inserção da plataforma no âmbito nacional também veio acompanhada de grande polêmica, evidenciada principalmente pelo embate entre o sindicato dos taxistas e a empresa.

E, ao que parece, isso ainda está longe de acabar. Narra Trindade (2016) que "representantes da categoria de diversos estados da federação reuniramse para protestar em Curitiba. Eles foram recebidos por Sérgio Moro, na sede da Justiça Federal, ocasião em que lhe entregaram um dossiê contra o aplicativo".

Os serviços prestados pelos táxis e pelo Uber, em certos aspectos, são similares, visto estarem ligados ao transporte individual de passageiros. Aliás, de acordo com relatos sobre a origem do aplicativo, sua concepção teve amparo justamente a partir de críticas à baixa qualidade dos táxis, sendo pensado como uma ferramenta alternativa moderna e ágil (MELLO, 2016, p. 779).

Ainda que ambos os serviços sejam voltados ao transporte individual remunerado de passageiro, há diferenças importantes, conforme explica Mello (2016, p. 779):

[...] O serviço de táxi possui diversas formas de 
acesso. Podemos tomar um táxi: (I) acenando para o taxista nas vias públicas (sistema de hailing), (II) dirigindo-nos até um ponto fixo de táxis (sistema de taxi rank), (III) telefonando para uma central telefônica que nos encaminha um táxi (sistema de taxi-booking) ou (IV) utilizando aplicativos para telefones celulares muito semelhantes ao aplicativo da UBER. Os serviços de transporte prestados por meio da UBER são diferentes das modalidades de serviço de táxi descritas em I, II e III. Por outro lado, são basicamente idênticos aos serviços prestados na modalidade IV.

Mesmo quando o sistema do taxi é utilizado por aplicativo persistem as diferenças. No caso do taxi, a corrida não precisa ser predefinida e a forma de pagamento poderá ser por cartão cadastrado, dinheiro, cartão de crédito ou débito, ao final do trajeto. Já no Uber, o trajeto sempre é predefinido e a forma de pagamento sempre é a mesma, mediante cartão previamente cadastrado.

Ora, sob o ponto vista econômico, ambos os sistemas operam no mercado do transporte individual de passageiros, existindo uma identidade conceitual genérica, algo como uma intersecção operacional, quando o táxi também opera por aplicativos.

Em outras palavras, ainda que exista um regime de competição entre os serviços, Mello (2016, p. 779) afirma não ser possível fixar o problema da concorrência sem uma investigação mais especializada, nesse sentido:

É possível que o modelo UBER crie uma demanda de serviço que não era produzida ou alimentada pelo serviço de táxi. É perfeitamente plausível conjecturar que pessoas que não fazem uso de táxi podem se 
sentir atraídas pela qualidade dos serviços prestados pela UBER. Nesse caso, o ingresso da UBER no setor econômico de transporte individual de passageiros remunerado não afetaria o serviço de táxi. Ainda assim, também parece possível presumir que muitos usuários de táxi podem se sentir atraídos exatamente pela qualidade dos serviços prestados pelo novo modelo e, portanto, podem migrar completamente para o sistema da empresa ou usar alternativamente um ou outro modelo. Aceitas essas premissas, é evidente que os serviços de transporte individual de passageiros prestados por meio do aplicativo UBER competem com o serviço de táxi.

Outros fatores, de ordem econômica, também merecem destaque. Os serviços prestados pelos taxistas sempre gozaram de um regime monopolista por todo o mundo. Trata-se de, em suma, de uma corporação geralmente bastante organizada e, por isso, capaz de exercer pressão relevante sobre os governos locais. Certamente, o desejo pelo monopólio do transporte individual de passageiros explica a resistência dos taxistas à entrada do Uber nesse mercado.

Por outro lado, a nova plataforma de serviços de transporte possui uma natureza disruptiva, significando revolucionária para essa área da economia, já que ordinariamente apresenta uma melhor performance frente aos agentes tradicionais. Como bem explica Mello (2016, p. 781):

Os computadores aposentaram as maquinas de escrever. Os sites de procura na internet eliminaram as enciclopédias. Os serviços de streaming de música e filmes podem acabar com a indústria de CDs e DVDs e afetaram drasticamente o tradicionalíssimo mercado das salas de cinema. Sistemas de intermediação de locação de imóveis 
como o Airbnb ameaçam tanto o setor hoteleiro quanto o de corretagem de imóveis. Sempre houve e há resistência a inovações disruptivas, entretanto a assimilação de novas tecnologias dificilmente pode ser contida, justamente porque recebe a adesão voluntária do público consumidor, que tende a valorizar as vantagens oferecidas pela inovação sem se preocupar com os efeitos negativos que a migração causa aos setores tradicionais.

Ante essas premissas, ao compararem ambos os serviços, os consumidores verificam certas vantagens da prestação por meio do Uber, o qual vem tirando proveito da inovação tecnológica. Calha anotar que os usuários dos táxis usualmente reclamam de vários aspectos desse serviço. Aliás, esse conjunto de elogios ao Uber e críticas aos táxis é internacional, não ocorre só nas cidades brasileiras.

No que toca ao aspecto jurídico, é preciso uma reflexão, partindo-se da Constituição Federal de 1988, e, em seguida, partindo-se para as legislações ordinárias que tocam o tema.

A Carta Magna da República adotou como modelo econômico o capitalismo, com ênfase na liberdade de iniciativa, livre concorrência e defesa do consumidor. É o que se depreende do artigo $1^{\circ}$, inciso IV e artigo 170, incisos IV, V e parágrafo único.

De outro lado, de acordo com a leitura do artigo 173 (que cuida das exceções à livre-iniciativa), combinado com o artigo 174 ( $\square$ como agente indicativo para o setor privado"), o sistema autoriza o livre exercício da atividade econômica independentemente de autorização, remetendo as exceções à previsão legal, conforme prevista no regime de distribuição de competências legislativas, previstos na Constituição. (BRASIL, 1988).

Seguindo o raciocínio, estabelece o artigo 21, inciso $\mathrm{XX}$, a competência da União para: "instituir diretrizes para o desenvolvimento urbano, inclusive habitação, saneamento básico e transportes urbanos"; 
prevendo o artigo 22, incisos I e XI, a competência da legislativa da União para: "direito civil" e "trânsito e transporte". Por fim, o artigo $30 \mathrm{da}$ CF atribui ao Município a competência para disciplinar assuntos locais. Fixados os textos constitucionais, passemos aos textos legais. (BRASIL, 1988).

Reza o artigo 730 do Código Civil: "pelo contrato de transporte alguém se obriga, mediante retribuição, a transportar, de um lugar para outro, pessoas ou coisas". Já o artigo 731 do mesmo Código estatui que "o transporte exercido em virtude de autorização, permissão ou concessão, rege-se pelas normas regulamentares e pelo que for estabelecido naqueles atos, sem prejuízo do disposto neste Código". (BRASIL, 2002).

Portanto, se o transporte não for exercido mediante autorização, permissão e concessão, não há que se falar na expedição de normas regulamentares expedidas por autoridades locais, ao menos no que se refere à exigência de prévia licença para o exercício da atividade, visto estar em cena um serviço eminentemente privado.

De outra banda, as Leis 12.468/2011 e 12.587/2012, usualmente invocadas pelos taxistas como argumento para impedir o funcionamento do Uber, não possuem qualquer pertinência para este propósito. A primeira, voltada exclusivamente para regulação dos taxistas, além de não revogadora do Código Civil, versa especificamente sobre esta profissão, qualificando-a de transporte público individual (art. $2^{\circ}$ ).

A segunda, ao estabelecer a Política Nacional de Mobilidade Urbana, cingese a definir o que é transporte motorizado privado, qualificando-o como o "meio motorizado de transporte de passageiros utilizado para a realização de viagens individualizadas por intermédio de veículos particulares".

Ora o transporte realizado por intermédio do Uber encaixa-se como uma luva nessa definição. É o que também ocorre, por exemplo, quando alguém contrata um motorista para levar a noiva ao casamento. Simples transporte motorizado privado. O fato de ser intermediado por uma plataforma eletrônica, no caso o Uber, não tem o 
condão de modificar a respectiva natureza jurídica, eis que dada por lei.

Na mesma linha de pensamento, são as observações de Andrigh (2016, p. 415):

Como se vê, o "transporte público individual" difere do "transporte privado individual", porque o primeiro é "aberto ao público", isto é, no "transporte público individual" há obrigatoriedade de atendimento universal, razão pela qual o taxista não pode recusar o passageiro ou o trajeto por ele solicitado; ao passo que no "transporte privado individual" impera a autonomia da vontade do motorista, que tem o direito de aceitar firmar o contrato de transporte com o consumidor, de acordo com a sua conveniência.

Com vistas a regulamentar a referida Lei 12.587/2012, o Município de São Paulo editou o Decreto 56.981, de 10 de maio de 2016, cujo artigo $1^{\mathrm{o}}$ determinou:

Art. $1^{\circ}$ Este decreto regulamenta os artigos $12 \mathrm{e}$ 18, I, da Lei Federal $n^{\circ} 12.587$, de 3 de janeiro de 2012, disciplinando o uso intensivo do viário urbano no Município de São Paulo para exploração de atividade econômica privada de transporte individual remunerado de passageiros de utilidade pública e regula o serviço de carona solidária e de compartilhamento de veículo sem condutor no Município.

Parágrafo único. Este decreto não se aplica aos serviços previstos na Lei Municipal $n^{\circ} 7.329$, de 11 de julho de 1969. (SÃO PAULO, 2016).

Por sua vez, o parágrafo único do artigo $1^{\circ}$ da citada Lei Municipal 7.329/69, estipula que: 
O transporte individual de passageiros, no Município, em veículos de aluguel providos de taxímetro, constitui serviço de interesse público, que somente poderá ser executado mediante prévia e expressa autorização da Prefeitura, a qual será consubstanciada pela outorga de Termo de Permissão e Alvará de Estacionamento, nas condições estabelecidas por esta lei e demais atos normativos que sejam expedidos, pelo Executivo. (SÃO PAULO, 1969).

Como se vê, o aludido Decreto deixou claro que o Uber e os táxis, a despeito de atenderem ao transporte individual de passageiros são dotados de natureza jurídica distinta, sendo o primeiro de utilidade pública e o segundo de interesse público.

No entanto, seria possível inclusive questionar a competência municipal para editar esse tipo de regulamentação. Porém, desde que não impediu pura e simplesmente o exercício da atividade do transporte motorizado privado, seja por intermédio do Uber ou outro aplicativo qualquer, seja mesmo sem a intermediação de quem quer que seja, não nos parece tenha havido usurpação da competência federal disciplinar as modalidades de transporte juridicamente aceitas.

Por fim, é de se convir que o assunto é novo e ainda deverá gerar $\square$ muito pano para a manga $\square$. Tanto é que, por exemplo, ainda pende de julgamento final o mandado de segurança movido pelo Uber contra o Diretor de Trânsito de São Paulo, onde consta alegação de que o teor do regulamento carece de especificações, e, quando muito, somente vetou autuações e apreensões de veículos pelo mero exercício da atividade econômica (autos $n^{\circ} 1041907-51.2015 .8 .26 .0053$, da $4^{\mathrm{a}}$ Vara da Fazenda Pública de São Paulo) ${ }^{1}$.

\section{CONCLUSÃO}

A humanidade vive a chamada era da sociedade da informação, período marcado pela crescente circulação de ideias, dados, informações e conhecimento, fenômeno impulsionado pelo avanço tecnológico ocorrido nas últimas décadas que

1 Disponível em: <https://esaj.tjsp.jus.br/>. 
possibilitou o surgimento de equipamentos eletrônicos como tablets e smartphones que permitem amplo acesso à internet.

Toda essa efervescência tecnológica vem contribuindo para o surgimento de serviços até então nunca imaginados, como é o caso do aplicativo Uber que, em suma, opera como um intermediário que, por aproximar as partes, facilita a contratação do transporte de pessoas, requerendo, para tanto, que motorista e passageiro estejam previamente cadastrados no sistema.

O Uber está cada vez mais presente nas maiores cidades do mundo, o que tem gerado conflitos, notadamente com os taxistas, cujo mercado, até então cativo dessa classe de profissionais, começa a ser dividido com os motoristas usuários do Uber, cujos passageiros encontram-se bastante satisfeitos com as facilidades do aplicativo.

A Constituição de 1988 prevê, mesmo que com atenuações, o regime capitalista de mercado (arts. $1^{\circ}$, IV; 170, IV, V e parágrafo único), sendo livre o exercício da atividade econômica independentemente de autorização do Poder Público, salvo nos casos previstos em lei, segundo as competências distribuídas entre os entes federativos.

Desse modo, cabe à União (art. 21, XX, da CF/88), por meio de lei, instituir diretrizes para os transportes urbanos; sendo também de sua competência, a teor do art. 22, I e XI, legislar sobre "direito civil" e "trânsito e transporte". Os Municípios, por sua vez, são competentes para disciplinar os assuntos de interesse local (art. 30) (BRASIL, 1988).

Nos termos da legislação em vigor (artigos 730 e 731 do Código Civil e Leis 12.468/2011 e 12.587/2012), enquanto o transporte realizado por taxis é qualificado como público individual, o intermediado pelo Uber possui a natureza de privado individual, o que, juridicamente, os diferencia, inclusive no que tange à necessidade de prévia e expressa 
autorização do Poder Público apenas para os primeiros (táxis).

Dessa maneira, as leis locais (municipais) não podem impedir ou mesmo limitar o funcionamento do aplicativo Uber, sob pena de violação não apenas da competência constitucional da União para legislar sobre transporte, como também das leis federais que já tratam da matéria.

No Município de São Paulo, com vistas a regulamentar a Lei 12.587/2012, sobreveio o Decreto Municipal 56.981, de 10 de maio de 2016, que reconheceu o transporte por meio dos táxis como sendo de utilidade pública e reconheceu aquele intermediado pelo Uber como de interesse público (SÃO PAULO, 2016).

Não se vislumbra no indigitado Decreto 56.981 indícios de desrespeito à Constituição ou às leis federais que disciplinam o transporte de pessoas, visto não ter a normatização em epígrafe simplesmente vedado o exercício de atividade econômica sob a intermediação do Uber ou outro aplicativo qualquer, ou mesmo ter imposto sanções pelo exercício dessa atividade.

É certo, contudo, que há polêmicas que ainda persistem, destacando-se que pende de julgamento final perante o Tribunal de Justiça de São Paulo mandado de segurança onde se afirma que o Decreto 56.981 carece de especificações, e, quando muito, somente vetou autuações e apreensões de automóveis pela simples utilização do Uber.

\section{REFERÊNCIAS}

ANDRIGH, Fátima Nancy. Uber: a regulação de aplicativos de intermediação de contrato de transporte. Revista de Direito Administrativo, Rio de Janeiro, v. 271, p. 409-416, jan./abr. 2016.

BARROS, Ana Cirne Paes de. Uber: o consumo colaborativo e as lógicas do mercado. In: CONGRESSO INTERNACIONAL - COMUNICAÇÃO E CONSUMO, 5., 2015, São Paulo. Disponível em: <http://anais-comunicon2015.espm.br/GTs/GT5/24_GT5 BARROS.pdf $>$. Acesso em: 1 jul. 2016. 
BAUMANN, Renato. Uma visão econômica da globalização. In: 1996. . O Brasil e a economia global. Rio de Janeiro: SOBEET, BOTSMAN, R.; ROGERS, R. O Que é meu é seu: como o consumo colaborativo vai mudar o nosso mundo. Porto Alegre: Bookman, 2011.

BRASIL. Código Civil Brasileiro. Lei n. 10.406, de 10 de janeiro de 2002. Disponível em: <http://www.planalto.gov.br/ccivil_03/ leis/2002/L10406.htm>. Acesso em: 01 jul. 2016.

\section{BRASIL. Constituição (1988). Constituição da República}

Federativa do Brasil. Disponível em: <http://www.planalto.gov.br/ ccivil_03/constituicao/constituicaocompilado.htm>. Acesso em:1 jul. 2016.

BRASIL. Lei $\mathbf{n}^{\circ} \mathbf{1 2 . 4 6 8}$, de 26 de agosto de 2011. Regulamenta a profissão de taxista; altera a Lei no 6.094, de 30 de agosto de 1974; e dá outras providências. Disponível em: <http://www.planalto.gov.br/ ccivil_03/_Ato2011-2014/2011/Lei/L12468.htm>. Acesso: 1 jul. 2016.

BRASIL. Lei no 12.587, de 3 de janeiro de 2012. Disponível em: $<$ http://www.planalto.gov.br/ccivil_03/_ato2011-2014/2012/lei/ 112587.htm>. Acesso em: 1 jul. 2016.

BRASIL. Lei no 12.865, de 9 de outubro de 2013. Institui as diretrizes da Política Nacional de Mobilidade Urbana; revoga dispositivos dos Decretos-Leis nos 3.326, de 3 de junho de 1941, e 5.405, de 13 de abril de 1943, da Consolidação das Leis do Trabalho (CLT), aprovada pelo Decreto-Lei no 5.452, de 1o de maio de 1943, e das Leis nos 5.917, de 10 de setembro de 1973, e 6.261, de 14 de novembro de 1975; e dá outras providências. Disponível em: $<$ http://www.planalto. gov.br/ccivil_03/_ato2011-2014/2013/lei/112865.htm>. Acesso em: 1 jul. 2016. 
BRASIL. Lei no 12.965, de 23 de abril de 2014. Estabelece princípios, garantias, direitos e deveres para o uso da Internet no Brasil.

Disponível em: <http://www.planalto.gov.br/ccivil_03/_ato20112014/2014/lei/112965.htm>. Acesso em: 1 jul. 2016.

COOPER, G. et al. Mobile Society? Technology, distance, and presence. In: WOOLGAR, S. Virtual Society. Oxford: Oxford Press, 2002.

GOMES, Helton Simões. Conexão internet smartphone dobra no Brasil. Disponível em: <http://g1.globo.com/tecnologia/noticia/2015/08/conexao-internet-smartphonedobra-no-brasil-em-2015-diz-google.html>. Acesso em: 7 jul. 2016.

IANNI, Octávio. Teorias da globalização. 3. ed. Rio de Janeiro: Civilização Brasileira, 1996.

MELLO, Cláudio Ari. O futuro da mobilidade urbana e o caso UBER. Revista de Direito da Cidade, Rio de Janeiro, v. 8, n. 2, p. 775-812, 2016.

MOREIRA, Rômulo de Andrade. Globalização e crime. In: LEÃO, Aldroaldo; PANPLONA

FILHO, Rodolfo. Globalização e direito. Rio de Janeiro: Forense. 2002.

NÚMERO de smartphones em uso no Brasil chega a 168 milhões, diz estudo. Disponível em: <http://www1.folha.uol.com.br/ mercado/2016/04/1761310-numero-de-smartphones-em-uso-nobrasil-chega-a-168-milhoes-diz-estudo.shtml $>$. Acesso em: 1 jul. 2016.

O'BRIEM, Sara Ashley. Uber is the most valuable startup in the world. 2015. Disponivel em: <http://money.cnn.com/2015/07/31/ 
technology/uber-50-billion-valuation/index.h tml?iid=hp-topleaddom>. Acesso em: 7 jul. 2016.

\section{PAESANI, Liliana Minardi. Direito e Internet: liberdade de} informação, privacidade e responsabilidade civil. 6 . ed. São Paulo: Atlas, 2013.

SANTOS, Boaventura de Sousa. A globalização e as ciências sociais. São Paulo: Cortez, 2011.

SÃO PAULO. Lei do Município no ${ }^{\mathbf{7} .329}$, de 11 de junho de 1969. Disponível em: <http://www.prefeitura.sp.gov.br/cidade/secretarias/ transportes/institucional/index. php? $\mathrm{p}=6997>$. Acesso em: $12 \mathrm{jul}$. 2016.

SÃO PAULO. Decreto do Município no 56.981 , de 10 de maio de 2016. Disponível em: <http://www3.prefeitura.sp.gov. $\mathrm{br} / \mathrm{cadlem} / \mathrm{secretarias} /$ negocios juridicos/cadlem/ integra. asp?alt=11052016D\%20569810000>. Acesso em: 12 jul. 2016.

SILVA, Laize Andréa de Souza; ANDRADE, Maurício Oliveira de. Barreiras regulamentares para implantações de sistemas de "carona remunerada" no Brasil. In: CONGRESSO

NACIONAL DE PESQUISA EM TRANSPORTE DAANPET, 29., 2015, Ouro Preto. Disponível em: <http://www.anpet.org.br/xxixanpet/anais/documents/ AC572.pdf $>$. Acesso em: 15 out. 2016.

TAKAHASHI, Takeo. Sociedade da informação no Brasil: livro verde. Brasília: Ministério da Ciência e Tecnologia, 2000. Disponível em: $<$ https://www.governoeletronico.gov.br/ documentos-e-arquivos/ livroverde.pdf $>$. Acesso em: 15 out. 2016. 
TRINDADE, André Karam. Taxistas vão a Moro contra a Uber (e o direito fica cada vez menor). Disponível em: <http://www.conjur.com.br/2016-jul-09-classe-taxistasmoro-uber-direito-fica-cada -vez-menor>. Acesso em: 9 jul. 2016.

UBER. A encontrar o caminho: a criar possibilidades para os passageiros, os motoristas e as cidades: nosso histórico de viagem. 2016. Disponível em: $<$ https://www.uber.com/ pt/our-story/>. Acesso em: 22 set. 2016.

WULF, Christoph. Globalização universalizante ou diferenciada?. In: BARRET-DUCROCQ, Françoise (Org.). Globalização para quem? uma discussão sobre os rumos da globalização São Paulo: Futura, 2004.

Como citar: MARTINS, Marcelo Guerra; NASCIMENTO, Marcelo Tadeu; MACHADO, Rony Max. Os Novos Serviços na Sociedade da Informação: o Caso do Uber na Cidade de São Paulo. Scientia Iuris, Londrina, v. 21, n. 2, p. 154-181, jul. 2017. DOI: 10.5433/2178-8189.2017v21n1p154. ISSN: 2178-8189.

Recebido em: 09/11/2016

Aprovado em: 06/03/2017 